\title{
A sigh of relief: vaccine-associated hypermetabolic lymphadenopathy following the third COVID-19 vaccine dose is short in duration and uncommonly interferes with the interpretation of $\left[{ }^{18} \mathrm{~F}\right] \mathrm{FDG}$ PET-CT studies performed in oncologic patients
}

\author{
Dan Cohen $^{1}$ (D) Shir Hazut Krauthammer ${ }^{1} \cdot$ Ido Wolf $^{2,3} \cdot$ Einat Even-Sapir ${ }^{1,3}$ (D)
}

Received: 30 August 2021 / Accepted: 28 September 2021 / Published online: 15 October 2021

(c) The Author(s), under exclusive licence to Springer-Verlag GmbH Germany, part of Springer Nature 2021

\begin{abstract}
Purpose The incidence of COVID-19 vaccine-associated hypermetabolic lymphadenopathy (VAHL) is high following the administration of the first and second BNT162b2 vaccine doses. The impact of this finding on $\left[{ }^{18} \mathrm{~F}\right] \mathrm{FDG}$ PET-CT interpretation and its correlation with the induced humoral immunity have been reported. Assuming the amnestic immune response is different following the third vaccine dose, we aimed to explore the incidence of VAHL over time after the third BNT162b2 dose administration, and its relevance to $\left[{ }^{18} \mathrm{~F}\right] \mathrm{FDG}$ PET-CT interpretation in oncologic patients.

Methods A total of 179 consecutive oncologic patients that underwent $\left[{ }^{18} \mathrm{~F}\right]$ FDG PET-CT after a third BNT162b2 vaccine dose were included. The presence of VAHL was assessed. On VAHL-positive scans, the SUVmax, number, location, and size of the "hot" nodes were recorded. The median time interval between vaccination and imaging was 8 (IQR, 5-14) days. Results The incidences of all-grade VAHL and grade 3-4 VAHL were $47.5 \%$ and $8.9 \%$, respectively. VAHL was identified on $82.5 \%$ of studies performed within the first 5 days from vaccination. Grade 3-4 VAHL was observed on $28.1 \%$ of studies performed within the first 5 days from vaccination, but was not detected on studies performed more than 5 days from vaccination. Separation between VAHL and malignant lymphadenopathy was not possible in only 2 of the 179 study patients. On a multivariable logistic regression, independent predictors of grade 3-4 VAHL were short time interval between vaccination and imaging $(P \mathrm{v}<0.01)$, younger age $(P \mathrm{v}<0.01)$, and lower BMI $(P \mathrm{v}=0.03)$.

Conclusion VAHL is commonly identified on $\left[{ }^{18} \mathrm{~F}\right] \mathrm{FDG}$ PET-CT performed within the first 5 days from the third BNT162b2 vaccine dose administration. High-grade VAHL is unlikely to be observed on a scan performed 6 days or longer from vaccination, and is even less likely in older and obese patients.
\end{abstract}

Keywords COVID-19 · Vaccination · Lymphadenopathy $\cdot$ Immune response $\cdot$ Oncologic imaging

This article is part of the Topical Collection on OncologyGeneral

Einat Even-Sapir

evensap@tlvmc.gov.il

1 Department of Nuclear Medicine, Tel-Aviv Sourasky Medical Center, 6 Weizmann St, 6423906 Tel Aviv, Israel

2 Institute of Oncology, Tel-Aviv Sourasky Medical Center, 6 Weizmann St, 6423906 Tel Aviv, Israel

3 Sackler Faculty of Medicine, Tel Aviv University, Tel Aviv, Israel

\begin{tabular}{|c|c|}
\hline \multicolumn{2}{|l|}{ Abbreviations } \\
\hline SARS-CoV-2 & $\begin{array}{l}\text { Severe acute respiratory syndrome corona- } \\
\text { virus } 2\end{array}$ \\
\hline COVID-19 & Coronavirus disease 2019 \\
\hline mRNA & Messenger ribonucleic acid \\
\hline VAHL & $\begin{array}{l}\text { Vaccine-associated hypermetabolic } \\
\text { lymphadenopathy }\end{array}$ \\
\hline $\mathrm{EqHL}$ & $\begin{array}{l}\text { Equivocal hypermetabolic } \\
\text { lymphadenopathy }\end{array}$ \\
\hline$\left[{ }^{18} \mathrm{~F}\right] \mathrm{FDG}$ & $\mathrm{F}^{18}$-fluorodeoxyglucose \\
\hline PET-CT & $\begin{array}{l}\text { Positron emission tomography-computed } \\
\text { tomography }\end{array}$ \\
\hline SUVmax & Maximum standardized uptake value \\
\hline MIP & Maximal intensity projection \\
\hline & Body mass index \\
\hline
\end{tabular}

Abbreviations virus 2

Messenger ribonucleic acid

Vaccine-associated hypermetabolic

lymphadenopathy

Equivocal hypermetabolic

lymphadenopathy

$\mathrm{F}^{18}$-fluorodeoxyglucose

tomography

Body mass index 


$\begin{array}{ll}P \mathrm{v} & P \text { Value } \\ \text { IQR } & \text { Interquartile range } \\ \text { OR } & \text { Odds ratio } \\ \text { CI } & \text { Confidence interval } \\ \text { CD20 } & \text { Cluster of differentiation 20 }\end{array}$

\section{Introduction}

Vaccination against SARS-CoV-2 has become one of the main strategies to control the evolving COVID-19 pandemic. Since late 2020, mass COVID-19 vaccination campaigns are being conducted around the world. In Israel, the two-dose regimen of the Pfizer BNT162b2 mRNA vaccine [1], given 21 days apart, was the most common vaccination regimen [2].

Emerging new SARS-CoV-2 variants [3] as well as evidences of lower vaccine-induced immunogenicity in some patient populations [4-6] are among the causes that raised a need to consider a third vaccine dose administration. The administration of a third BNT162b2 dose has started in Israel during July 2021, first in patients $>60$ years and later in younger populations. As of the end of August 2021, more than 1.92 million people have received the third vaccine dose [7].

During the mass vaccination with the first and second vaccine doses, our group and others reported the high incidence of the BNT162b2 vaccine-associated hypermetabolic lymphadenopathy (VAHL) on $\left[{ }^{18} \mathrm{~F}\right]$ FDG PET-CT studies. Following the second vaccine dose, we observed VAHL in $45.8 \%$ of the studies [8]. Eshet et al. reported that VAHL persisted in $29 \%$ of patients between 7 and 10 weeks after the second BNT162b2 dose [9]. Following the administration of the Moderna mRNA-1273 vaccine, Skawran et al. reported a VAHL incidence of $72 \%$ [10]. The finding of VAHL was found relevant when interpreting $\left[{ }^{18} \mathrm{~F}\right] \mathrm{FDG}$ PET-CT of oncologic patients [8, 10-13], more commonly in patients with breast cancer, lymphoma, and malignancies of the upper limb, when "hot" axillary nodes may reflect malignant involvement [8].

In a study our group conducted on patients with hematologic malignancy, we presented the positive correlation between the imaging finding of VAHL and the post-vaccination antibody titers. We concluded that VAHL on imaging may reflect a potent germinal center response in lymph nodes draining the vaccine injection site [14]. The relationship between VAHL and immune status was observed by Eifer et al. as well [15].

Assuming that the amnestic immune response following a third vaccine dose may differ from the response elicited by the first and second vaccine doses, we hypothesized that the characteristics of VAHL following the third dose are different from those previously reported. We therefore conducted this study to explore the incidence of VAHL over time after the third COVID-19 vaccine administration and its relevance to $\left[{ }^{18}\right.$ F]FDG PET-CT interpretation of oncologic patients.

\section{Methods}

\section{Patient population}

After receiving the consent of the institutional ethical committee, all oncologic patients over 16 years of age that underwent whole-body $\left[{ }^{18} \mathrm{~F}\right]$ FDG PET-CT in our department were interviewed regarding their COVID-19 vaccination status. Between August 1 and August 25, 2021, a total of 179 consecutive patients reported they had received a third BNT162b2 vaccine dose before imaging, and were included in the study. For each patient, we recorded the following parameters in the dataset: (1) the time interval between vaccination and imaging, and the vaccination site; (2) age, sex, and body mass index (BMI); (3) the indication for PET-CT, including type of malignancy and types of systemic anti-cancer therapies received during the 3 months prior to imaging.

Table 1 summarizes the characteristics of the study cohort.

\section{Imaging and categorization of lymphadenopathy}

$\left[{ }^{18} \mathrm{~F}\right]$ FDG PET-CT studies were performed on PET-CT scanners (GE Healthcare; DISCOVERY 690 and DISCOVERY $\mathrm{MI} ; 7$ to 8 frames; frame time $1.5-3 \mathrm{~min}$ ), according to our standard protocol, with the administration of a diluted oral contrast agent and injection of $3.7 \mathrm{MBq} / \mathrm{kg}\left[{ }^{18} \mathrm{~F}\right] \mathrm{FDG}$ approximately $60 \mathrm{~min}$ prior to the study. Final PET-CT interpretation was carried out by at least one nuclear medicine specialist with PET-CT experience of at least 8 years.

For each patient, the presence or absence of "hot" axillary or supraclavicular lymph nodes ipsilateral to the vaccine injection site was recorded. Based on the interpretation that appeared in the PET-CT report, the "hot" nodes were further categorized as benign vaccine-associated, malignant, or equivocal. VAHL was recorded if the lymphadenopathy was reported as benign vaccine-associated. In case the hypermetabolic lymphadenopathy could not be confidently categorized as neither benign vaccine-associated nor malignant, the case was recorded as equivocal. The type and site of the primary tumor, the stage of the disease, the presence and location of other abnormal findings (mainly malignant lymphadenopathy in other nodal stations), and findings on previous studies were all considered when interpreting the nature of the hypermetabolic lymphadenopathy.

In all VAHL cases, the number of the "hot" nodes, their location, the size of the biggest "hot" node (short-axis diameter), and the $\left[{ }^{18} \mathrm{~F}\right] \mathrm{FDG}$ uptake intensity measured in the 
Table 1 Patient characteristics

\begin{tabular}{|c|c|c|}
\hline & Variable & $\begin{array}{l}\text { All patients } \\
(n=179)\end{array}$ \\
\hline \multirow[t]{3}{*}{ General } & Female & $93(52 \%)$ \\
\hline & Age (years) & $71.5(65-78)$ \\
\hline & BMI $\left(\mathrm{kg} / \mathrm{m}^{2}\right)$ & $26.1(23.4-29.6)$ \\
\hline \multirow[t]{11}{*}{ Primary malignancy } & Hematologic malignancies & $32(18 \%)$ \\
\hline & $\begin{array}{l}\text { Lower gastrointestinal } \\
\text { cancers }\end{array}$ & $27(15 \%)$ \\
\hline & Breast cancer & $26(15 \%)$ \\
\hline & Lung cancers & $24(13 \%)$ \\
\hline & Skin cancers and sarcomas & $16(9 \%)$ \\
\hline & $\begin{array}{l}\text { Hepatobiliary-pancreatic } \\
\text { cancers }\end{array}$ & $14(8 \%)$ \\
\hline & Gynecological cancers & $13(7 \%)$ \\
\hline & Genitourinary cancers & $10(6 \%)$ \\
\hline & $\begin{array}{l}\text { Upper gastrointestinal } \\
\text { cancers }\end{array}$ & $8(5 \%)$ \\
\hline & Head and neck cancers & $4(2 \%)$ \\
\hline & Others & $5(3 \%)$ \\
\hline \multirow[t]{4}{*}{ PET-CT indication } & Staging & $36(20 \%)$ \\
\hline & Monitor response to therapy & $70(39 \%)$ \\
\hline & Recurrence detection & $20(11 \%)$ \\
\hline & Follow-up (with NED) & $53(30 \%)$ \\
\hline \multirow[t]{4}{*}{ Recent therapy } & $\begin{array}{l}\text { Any systemic anti-cancer } \\
\text { therapy }\end{array}$ & $70(39 \%)$ \\
\hline & Chemotherapy & $38(21 \%)$ \\
\hline & Biologic therapy & $33(18 \%)$ \\
\hline & Immunotherapy & $13(7 \%)$ \\
\hline
\end{tabular}

Categorical variables are reported as frequency and percentage. Continuous variables are reported as median and IQR. BMI, body mass index; $N E D$, no evidence of disease

"hottest" node (using maximal standardized uptake value (SUVmax)) were recorded. The presence or absence of a regional $\left[{ }^{18} \mathrm{~F}\right] \mathrm{FDG}$ uptake (higher than the background deltoid uptake) in the vaccination side reported by the patient was recorded as well. All VAHL cases were graded on the 4 grade scale described in our previous paper [8]: Grade 1, mild uptake intensity (SUVmax $<2.2$ ); Grade 2 , moderate uptake intensity $(2.2 \leq$ SUVmax $<4)$; Grade 3 , high uptake intensity (SUVmax $\geq 4$ ) in normal-size nodes; and Grade 4 , high uptake intensity (SUVmax $\geq 4$ ) in enlarged nodes. Grade 3-4 VAHL were considered high grade.

\section{Statistical analysis}

Categorical data were described with contingency tables that included frequency and percent. Continuous variables were evaluated for normal distribution and reported as mean \pm standard deviation (SD) or as median and interquartile range (IQR). Pearson's $\chi^{2}$ test and Fisher's exact test were applied to compare proportions between groups. The Mann-Whitney $U$ test was applied to compare medians of continuous variables between two groups. Univariate and bivariable logistic regression analyses were applied to study the association between possible predictors and VAHL status. A multivariable logistic regression analysis was performed in order to identify independent predictors of VAHL status. Variables with a trend or a significant association with VAHL status, as well as those known to be of important clinical significance, were tested in the multivariable model. A two-sided $P$ value of $<0.05$ was considered statistically significant. SPSS software (IBM SPSS Statistics for Windows, version 27, IBM corp., Armonk, NY, USA, 2017) was used for statistical analyses. Plots were generated using the open-source statistics software R (version 4.0.5, R Foundation for Statistical Computing).

\section{Results}

\section{VAHL characteristics following the third BNT162b2 vaccine dose}

With a median time interval of 8 (IQR, 5-14, range, 1-36) days between vaccination and imaging, $85(47.5 \%)$ of the patients had any-grade VAHL on their $\left[{ }^{18} \mathrm{~F}\right]$ FDG PET-CT studies. Only 16 (8.9\%) of the vaccinated patients had highgrade VAHL on imaging. Figure 1A illustrates the proportion of vaccinated patients that had VAHL on imaging and their VAHL grades at four time intervals post vaccination. All-grade VAHL was significantly more common on studies done during the first 5 days from vaccination compared to studies done $\geq 6$ days from vaccination $(82.5 \%$ vs $31.1 \%$, $P \mathrm{v}<0.01)$. Cases of grade 3-4 VAHL were only detected on scans performed during the first 5 days following vaccination (in $28.1 \%$ of studies, compared with $0 \%$ of studies done $\geq 6$ days from vaccination, $P v<0.01$ ). Later than day 5 from vaccination, the incidence of VAHL decreased gradually. The incidence of VAHL on studies performed 11-15 days from vaccination was $17.6 \%$, and dropped to $2.8 \%$ on studies performed $\geq 16$ days from vaccination.

Table 2 summarizes the grade, SUVmax, number, location, and size of the VAHL cases reported after the third vaccine dose, as well as the rate of increased uptake in the vaccination site. VAHL on scans performed within the first 5 days from vaccination was of higher uptake intensity with significantly higher median SUVmax $(3.4$ vs $1.9, P v<0.01)$ and involved significantly higher number of "hot" nodes (median 4 vs $3, P v=0.03$ ). Supraclavicular involvement in VAHL was observed only on scans performed within 5 days from vaccination (in $15 \%$ of cases, compared with $0 \%$ of scans performed $\geq 6$ days from vaccination, $P \mathrm{v}=0.02$ ). 
A

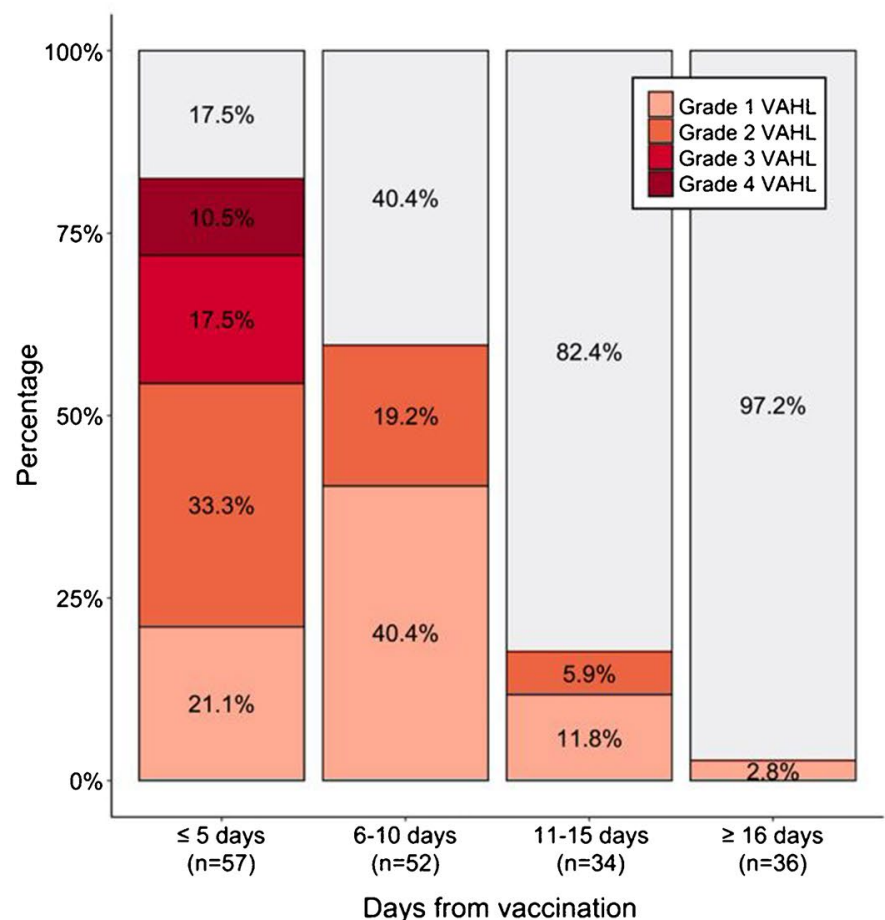

B

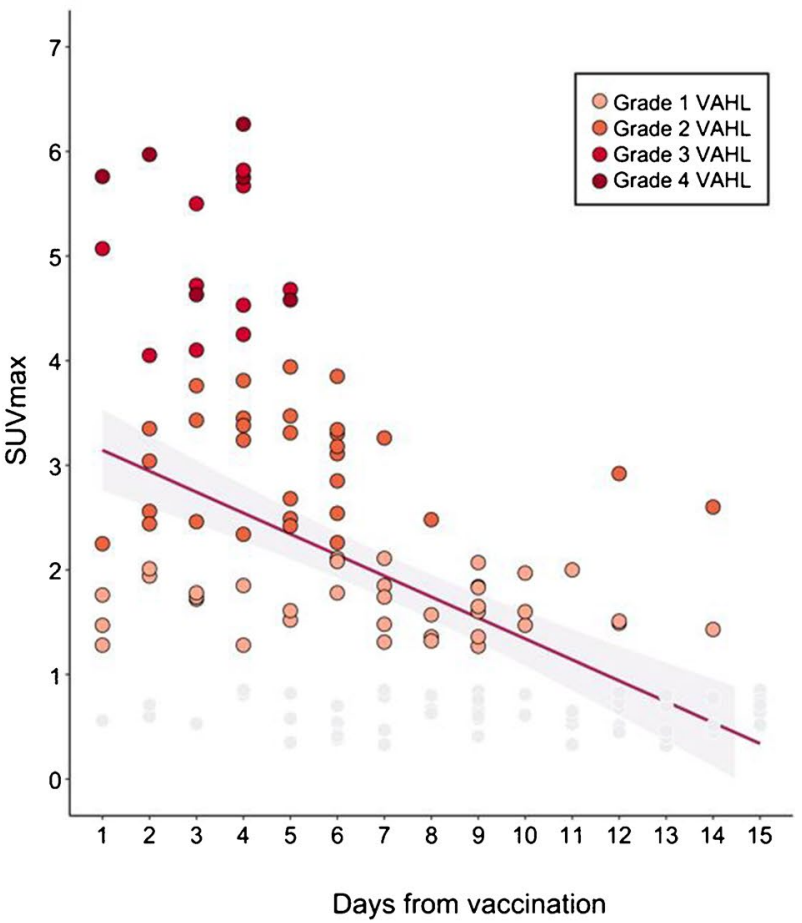

Fig. 1 Vaccine-associated hypermetabolic lymphadenopathy (VAHL) following the third COVID-19 vaccine dose. A Rates of VAHL and their grade at different time intervals from vaccination. B Distribution of SUVmax measured in VAHL cases over time from vaccination

Table 2 VAHL characteristics following the third COVID-19 vaccine dose

\begin{tabular}{|c|c|c|c|c|c|}
\hline & & $\begin{array}{l}\text { All VAHL cases } \\
(n=85)\end{array}$ & $\begin{array}{l}\text { VAHL cases } \leq 5 \text { days } \\
\text { from vaccination } \\
(n=47)\end{array}$ & $\begin{array}{l}\text { VAHL cases } \geq 6 \text { days } \\
\text { from vaccination } \\
(n=38)\end{array}$ & $P v$ \\
\hline \multirow[t]{2}{*}{ Grading } & Grade 1-2 VAHL & $69(81 \%)$ & $31(66 \%)$ & $38(100 \%)$ & $<0.01^{*}$ \\
\hline & Grade 3-4 VAHL & $16(19 \%)$ & $16(34 \%)$ & $0(0 \%)$ & $<0.01^{*}$ \\
\hline Intensity & SUVmax of the "hottest" node & $2.4(1.7-3.5)$ & $3.4(2.0-4.6)$ & $1.9(1.5-2.6)$ & $<0.01^{*}$ \\
\hline \multirow[t]{2}{*}{ Number } & Number of "hot" nodes & $3(2-5)$ & $4(2-6)$ & $3(2-4)$ & $0.03 *$ \\
\hline & Number of "hot" nodes $>3$ & $39(46 \%)$ & $26(55 \%)$ & $13(34 \%)$ & $0.05^{*}$ \\
\hline \multirow[t]{3}{*}{ Location } & Axilla- level 1 & $85(100 \%)$ & $47(100 \%)$ & $38(100 \%)$ & $>0.99$ \\
\hline & Axilla - level 2/3/interpectoral & $35(41 \%)$ & $23(49 \%)$ & $12(32 \%)$ & 0.11 \\
\hline & Supraclavicular & $7(8 \%)$ & $7(15 \%)$ & $0(0 \%)$ & $0.02 *$ \\
\hline Size & Enlarged lymph node & $11(13 \%)$ & $7(15 \%)$ & $4(11 \%)$ & 0.75 \\
\hline Injection site & Increased uptake & $56(66 \%)$ & $42(89 \%)$ & $14(37 \%)$ & $<0.01^{*}$ \\
\hline
\end{tabular}

$P \mathrm{~V}$ refers to the comparison between the cases of VAHL observed $\leq 5$ days from vaccination and the cases of VAHL observed $\geq 6$ days from vaccination. Categorical variables are reported as frequency and percentage. Continuous variables are reported as median and IQR. VAHL, vaccineassociated hypermetabolic lymphadenopathy; SUVmax, maximum standardized uptake value

The overall 85 cases of VAHL had a median SUVmax of 2.4 (IQR 1.7-3.5). The distribution of SUVmax over time from vaccination is presented in Fig. 1B, illustrating the gradual decrease in $\left[{ }^{18} \mathrm{~F}\right] \mathrm{FDG}$ uptake intensity.

In only two cases $(1.1 \%)$ of the total vaccinated patients, the recent vaccination interfered with PET-CT interpretation: a patient referred for staging of upper limb melanoma, and a patient with an indolent lymphoma.

\section{Predictors of VAHL appearance on PET-CT scans (other than time from vaccination)}

On a univariate logistic regression, short time interval since vaccination was found predictive of the imaging identification of any-grade VAHL (OR, 0.73; 95\% CI, 0.67-0.80; $P \mathrm{v}<0.01)$ and of grade 3-4 VAHL (OR, 0.61; 95\% CI, $0.47-0.80 ; P \mathrm{v}<0.01)$. 
To identify other predictors of VAHL appearance on $\left[{ }^{18} \mathrm{~F}\right]$ FDG PET-CT, bivariable logistic regression analyses were performed (Table 3 ). Each analysis included two variables: the interval between vaccination and imaging, and the investigated variable. Beyond the time interval variable, younger age was identified as an independent predictor of all-grade VAHL and of high-grade VAHL $(P \mathrm{v}=0.01$ for both). BMI showed trends toward significance on the bivariable analyses for all-grade VAHL $(P v=0.08)$ and for high-grade VAHL $(P \mathrm{~V}=0.10)$. Types of malignancy and systemic therapies were not found predictive of VAHL.

On a multivariable logistic regression for grade 3-4 VAHL, days from vaccination (OR, 0.54; 95\% CI, $0.38-0.77 ; P \mathrm{v}<0.01$ ), age of the patient (OR, 0.90; 95\% CI, 0.83-0.97; $P \mathrm{v}<0.01$ ), and the BMI of the patient (OR, 0.83; 95\% CI, 0.70-0.98; $P \mathrm{v}=0.03$ ) were all identified as independent predictors. The model is detailed in Table 4. Indeed, patients with grade 3-4 VAHL were younger (median age 65.5 vs 72 years, $P \mathrm{v}=0.01$ ) and their median BMI was significantly lower $\left(23.9 \mathrm{vs} 26.1 \mathrm{~kg} / \mathrm{m}^{2}\right.$, $P \mathrm{v}=0.05)$.
Table 4 A multivariable model for prediction of grade 3-4 VAHL

\begin{tabular}{lrll}
\hline & \multicolumn{1}{l}{$P \mathrm{~V}$} & $\mathrm{OR}$ & $95 \% \mathrm{CI}$ \\
\hline Interval (days) & $<0.01^{*}$ & 0.54 & $0.38-0.77$ \\
Age (years) & $<0.01^{*}$ & 0.90 & $0.83-0.97$ \\
BMI $\left(\mathrm{kg} / \mathrm{m}^{2}\right)$ & $0.03^{*}$ & 0.83 & $0.70-0.98$ \\
\hline
\end{tabular}

A multivariable model for the prediction of grade 3-4 VAHL. The odds ratios (OR) with $95 \%$ confidence intervals (CI) of the independent predictors are presented

\section{Discussion}

The frequent appearance of VAHL on $\left[{ }^{18} \mathrm{~F}\right] \mathrm{FDG}$ PETCT studies in recently vaccinated oncologic patients has become a major concern in the era of the COVID-19 pandemic $[8,11-13]$.

The current study demonstrates that the overall incidence of any-grade VAHL following the third COVID-19 vaccine dose is basically similar to that reported following the first and second COVID-19 vaccine doses [8-10,

Table 3 Bivariable analyses for all-grade VAHL and grade 3-4 VAHL

\begin{tabular}{|c|c|c|c|c|c|c|c|}
\hline \multirow[t]{3}{*}{ Variable 1} & \multirow[t]{3}{*}{ Variable 2} & \multicolumn{3}{|c|}{ All grade VAHL } & \multicolumn{3}{|c|}{ Grade 3-4 VAHL } \\
\hline & & $P \mathrm{v}$ & OR & $95 \% \mathrm{CI}$ & & OR & $95 \% \mathrm{CI}$ \\
\hline & & \multicolumn{3}{|c|}{ (Numbers refer to variable 2) } & \multicolumn{3}{|c|}{ (Numbers refer to variable 2) } \\
\hline \multirow{18}{*}{$\begin{array}{l}\text { Interval between vaccina- } \\
\text { tion and imaging (days) }\end{array}$} & Gender (female) & 0.10 & 1.91 & $0.89-4.11$ & 0.31 & 1.85 & $0.57-6.06$ \\
\hline & Age (years) & $0.01 *$ & 0.93 & $0.89-0.98$ & $0.01 *$ & 0.92 & $0.86-0.98$ \\
\hline & $\mathrm{BMI}\left(\mathrm{kg} / \mathrm{m}^{2}\right)$ & 0.08 & 1.01 & $0.99-1.17$ & 0.10 & 0.88 & $0.76-1.03$ \\
\hline & Hematologic malignancies & 0.41 & 0.64 & $0.23-1.83$ & 0.42 & 0.40 & $0.04-3.77$ \\
\hline & Lower gastrointestinal cancers & 0.58 & 0.74 & $0.26-2.10$ & 0.72 & 0.74 & $0.14-3.96$ \\
\hline & Breast cancer & 0.83 & 1.12 & $0.39-3.25$ & 0.38 & 0.37 & $0.04-3.29$ \\
\hline & Lung cancers & 0.90 & 1.07 & $0.36-3.22$ & 0.62 & 0.65 & $0.12-3.56$ \\
\hline & Skin cancers and sarcomas & 0.15 & 0.40 & $0.11-1.39$ & 0.43 & 0.41 & $0.04-3.79$ \\
\hline & Hepatobiliary-pancreatic cancers & 0.23 & 2.29 & $0.59-8.93$ & 0.08 & 4.80 & $0.84-27.32$ \\
\hline & Gynecological cancers & 0.23 & 2.67 & $0.53-13.33$ & 0.58 & 1.77 & $0.23-13.59$ \\
\hline & Genitourinary cancers & 0.94 & 0.94 & $0.19-4.58$ & 0.99 & - & - \\
\hline & Upper gastrointestinal cancers & 0.94 & 1.07 & $0.18-6.32$ & 0.14 & 5.30 & $0.58-48.46$ \\
\hline & Head and neck cancers & 0.65 & 1.89 & $0.12-30.54$ & 0.15 & 8.69 & $0.46-162.69$ \\
\hline & Active malignancy & 0.50 & 0.74 & $0.31-1.77$ & 0.46 & 1.72 & $0.41-7.26$ \\
\hline & Recent systemic anti-cancer therapy & 0.30 & 0.66 & $0.30-1.45$ & 0.43 & 1.59 & $0.50-5.04$ \\
\hline & Recent chemotherapy & 0.77 & 0.87 & $0.35-2.18$ & 0.22 & 2.12 & $0.65-6.91$ \\
\hline & Recent biologic therapy & 0.41 & 0.68 & $0.27-1.71$ & 0.78 & 0.81 & $0.19-3.46$ \\
\hline & Recent immunotherapy & 0.57 & 0.64 & $0.14-2.92$ & 0.26 & 2.91 & $0.45-18.80$ \\
\hline
\end{tabular}

Each parameter was analyzed together with the time interval between vaccination and imaging on a bivariable logistic regression. Analyses were performed for the prediction of all-grade VAHL and grade 3-4 VAHL. The odds ratio (OR) with 95\% confidence interval (CI) for each analyzed variable are presented for the prediction of all-grade VAHL and grade 3-4 VAHL. VAHL, vaccine-associated hypermetabolic lymphadenopathy; $B M I$, body mass index. Active malignancy, this variable was considered positive in cases of treatment-naïve patients, those who received recent anti-cancer therapy, and those with recurrent disease identified on their $\left[{ }^{18} \mathrm{~F}\right]$ FDG PET-CT scan. Recent therapy was considered if given during the 3 months before the scan 
14-16]. However, VAHL cases following the third dose were found to have shorter duration and low uptake intensity after the first 5 days from vaccination. VAHL following a third vaccination does not usually persist for weeks, and only rarely interferes with imaging interpretation.

In view of these findings, previous published recommendations to postpone imaging to even 6 weeks away from vaccination [13] are not applicable after the third vaccine dose, and we recommend to schedule $\left[{ }^{18} \mathrm{~F}\right]$ FDG PET-CT for oncologic patients starting 6 days from the third BNT162b2 vaccine dose.

Advising oncologic patients to be vaccinated in the arm contralateral to the tumor expected nodal drainage is still relevant in the context of the third COVID-19 vaccination. Actually, the two cases of equivocal reports included in the current study could have both been prevented had the vaccination sites been chosen as recommended [8].

The previously described association between VAHL and immunogenicity $[14,15]$ may be implied also in the results of the current study. Older age [17] and obesity [18] were both reported to be associated with weaker vaccine-induced immunity. The results of the current study that younger age and lower BMI are independent predictors of high-grade VAHL (which correlates with humoral immunity [14]) further strengthen the association between VAHL and the vaccine-induced immunity.

In this study, no association was found between systemic anti-cancer therapies and VAHL. It is not unlikely that such association does exist, but could not have been found in this study patients, whose anti-cancer therapies were heterogeneous. In particular, the association we previously reported between VAHL and anti-CD20-containing therapies [14] could not have been investigated in the current study. Only four cohort patients received such therapies in the year prior to vaccination, probably due to the published recommendation to postpone COVID-19 vaccination to at least 6 months after completion of anti-CD20-containing treatment [19].

The characteristics of VAHL following the first and second vaccine doses were reported to be different $[8,10,16]$. This probably reflects the difference between the immune response elicited by a first vaccine dose and the amnestic response induced by a booster given 3 weeks later. Unlike the naïve cells involved in the primary immune response following a first vaccination, the memory $\mathrm{B}$ cell and $\mathrm{T}$ cell responses are different following booster vaccinations [20]. The memory cells have already undergone clonal expansion, differentiation, and affinity maturation, so the amnestic immune response has a minimal lag period. The VAHL characteristics observed in the current study correspond to the lymph node reaction to a booster given several months after a previous dose, probably reflecting the transient lymph node involvement in the tertiary immune response. At this point in the management of the COVID-19 pandemic, it is still unclear whether more vaccine doses will be indicated in the future. In case another dose will be recommended several months apart from a previous dose, it seems possible that the incidence and characteristics of VAHL described in the current study will be the most relevant in clinical practice.

\section{Conclusions}

VAHL is common during the first 5 days following the administration of the third BNT162b2 vaccine dose. Highgrade VAHL is unlikely to be observed on $\left[{ }^{18} \mathrm{~F}\right] \mathrm{FDG}$ PET$\mathrm{CT}$ performed at least 6 days from inoculation of the third vaccine dose, and is even less likely in older and obese patients. Albeit the low risk of equivocal findings on $\left[{ }^{18} \mathrm{~F}\right]$ FDG PET-CT in the context of the third COVID-19 vaccine dose, oncologic patients should be advised about the timing of imaging and about the site of vaccination, especially those with potential axillary tumor involvement.

Data availability The datasets used and/or analyzed during the current study are available from the corresponding author on reasonable request.

\section{Declarations}

Ethics approval and consent to participate All procedures performed in studies involving human participants were in accordance with the ethical standards of the institutional and/or national research committee and with the 1964 Helsinki Declaration and its later amendments or comparable ethical standards. This article does not contain any studies with human participants or animals performed by any of the authors. This retrospective study protocol was approved by the local institutional ethics committee which waived written informed consent (Reference ID 0056-21-TLV).

Consent for publication Not applicable.

Competing interests The authors declare no competing interests.

\section{References}

1. Polack FP, Thomas SJ, Kitchin N, Absalon J, Gurtman A, Lockhart S, Perez JL, Pérez Marc G, Moreira ED, Zerbini C, Bailey R. Safety and efficacy of the BNT162b2 mRNA COVID19 vaccine. N Engl J Med. 2020;383(27):2603-15. https://doi.org/ 10.1056/NEJMoa2034577.

2. Dagan N, Barda N, Kepten E, Miron O, Perchik S, Katz MA, Hernán MA, Lipsitch M, Reis B, Balicer RD. BNT162b2 mRNA COVID-19 vaccine in a nationwide mass vaccination setting. $\mathrm{N}$ Engl J Med. 2021. https://doi.org/10.1056/NEJMoa2101765.

3. Abdool Karim SS, de Oliveira T. New SARS-CoV-2 variantsclinical, public health, and vaccine implications. N Engl J Med. 2021;384(19):1866-8. https://doi.org/10.1056/NEJMc2100362.

4. Thakkar A, Gonzalez-Lugo JD, Goradia N, Gali R, Shapiro LC, Pradhan K, Rahman S, Kim SY, Ko B, Sica RA, Kornblum N. 
Seroconversion rates following COVID-19 vaccination amongst patients with cancer. Cancer Cell. 2021. https://doi.org/10.1016/j. ccell.2021.06.002.

5. Herishanu Y, Avivi I, Aharon A, Shefer G, Levi S, Bronstein Y, Morales M, Ziv T, Shorer Arbel Y, Scarfo L, Joffe E. Efficacy of the BNT162b2 mRNA COVID-19 vaccine in patients with chronic lymphocytic leukemia. Blood. 2021;137(23):3165-73. https://doi.org/10.1182/blood.2021011568.

6. Addeo A, Shah PK, Bordry N, Hudson RD, Albracht B, Di Marco M, Kaklamani V, Dietrich PY, Taylor BS, Simand PF, Patel D. Immunogenicity of SARS-CoV-2 messenger RNA vaccines in patients with cancer. Cancer Cell. 2021. https://doi.org/10.1016/j. ccell.2021.06.009.

7. Israel Ministry of health. COVID-19 in Israel - dashboard data. https://datadashboard.health.gov.il/COVID-19/general. Accessed August 25, 2021.

8. Cohen D, Krauthammer SH, Wolf I, Even-Sapir E. Hypermetabolic lymphadenopathy following administration of BNT162b2 mRNA COVID-19 vaccine: incidence assessed by [18 F] FDG PET-CT and relevance to study interpretation. Eur J Nucl Med Mol Imaging. 2021;48(6):1854-63. https://doi.org/10.1007/ s00259-021-05314-2.

9. Eshet Y, Tau N, Alhoubani Y, Kanana N, Domachevsky L, Eifer M. Prevalence of increased FDG PET/CT axillary lymph node uptake beyond 6 weeks after mRNA COVID-19 vaccination. Radiology. 2021;27: 210886. https://doi.org/10.1148/radiol.20212 10886.

10. Skawran S, Gennari AG, Dittli M, Treyer V, Muehlematter UJ, Maurer A, Burger IA, Mader C, Messerli O, Grünig H, Gebhard C. [18F] FDG uptake of axillary lymph nodes after COVID-19 vaccination in oncological PET/CT: frequency, intensity, and potential clinical impact. Eur Radiol. 2021;22:1-9. https://doi. org/10.1007/s00330-021-08122-2.

11. Özütemiz C, Krystosek LA, Church AL, Chauhan A, Ellermann JM, Domingo-Musibay E, Steinberger D. Lymphadenopathy in COVID-19 vaccine recipients: diagnostic dilemma in oncology patients. Radiology. 2021;24: 210275. https://doi.org/10.1148/ radiol.2021210275.

12. Bolton RC, Terán AK, Erba PA, Giammarile F. Medical imaging in times of pandemic: focus on the cornerstones of successful imaging. Eur J Nucl Med Mol Imaging. 2021;48(6):1724-5. https://doi.org/10.1007/s00259-021-05331-1.
13. Becker AS, Perez-Johnston R, Chikarmane SA, Chen MM, El Homsi M, Feigin KN, Gallagher KM, Hanna EY, Hicks M, Ilica AT, Mayer EL. Multidisciplinary recommendations regarding post-vaccine adenopathy and radiologic imaging: radiology scientific expert panel. Radiology. 2021;24: 210436. https://doi.org/ 10.1148/radiol.2021210436.

14. Cohen D, Krauthammer SH, Cohen YC, Perry C, Avivi I, Herishanu Y, Even-Sapir E. Correlation between BNT162b2 mRNA COVID19 vaccine-associated hypermetabolic lymphadenopathy and humoral immunity in patients with hematologic malignancy. Eur J Nucl Med Mol Imaging. 2021;48(11):3540-49. https://doi.org/10. 1007/s00259-021-05389-X.

15. Eifer M, Tau N, Alhoubani Y, Kanana N, Domachevsky L, Shams J, Keret N, Gorfine M, Eshet Y. COVID-19 mRNA vaccination: age and immune status and its association with axillary lymph node PET/CT uptake. J Nucl Med. 2021. https://doi.org/10.2967/jnumed.121.262194.

16. Treglia G, Cuzzocrea M, Giovanella L, Elzi L, Muoio B. Prevalence and significance of hypermetabolic lymph nodes detected by 2-[18F] FDG PET/CT after COVID-19 vaccination: a systematic review and a meta-analysis. Pharmaceuticals. 2021;14(8):762. https://doi.org/10.3390/ph14080762.

17. Collier DA, Ferreira IA, Kotagiri P, Datir R, Lim E, Touizer E, Meng B, Abdullahi A, Elmer A, Kingston N, Graves B. Agerelated immune response heterogeneity to SARS-CoV-2 vaccine BNT162b2. Nature. 2021;30:1-9. https://doi.org/10.1038/ s41586-021-03739-1.

18. Pellini R, Venuti A, Pimpinelli F, Abril E, Blandino G, Campo F, Conti L, De Virgilio A, De Marco F, Di Domenico EG, Di Bella O. Obesity may hamper SARS-CoV-2 vaccine immunogenicity. medRxiv. 2021 Jan 1. https://doi.org/10.1101/2021.02.24.21251 664

19. Perry C, Luttwak E, Balaban R, Shefer G, Morales MM, Aharon A, Tabib Y, Cohen YC, Benyamini N, Beyar-Katz O, Neaman M. Efficacy of the BNT162b2 mRNA COVID-19 vaccine in patients with B-cell non-Hodgkin lymphoma. Blood Adv. 2021;5(16):3053-61. https://doi.org/10.1182/bloodadvances. 2021005094.

20. Abbas AK, Abbas AK, Lichtman AH, Pillai S. Cellular and molecular immunology. Elsevier; 2018.

Publisher's note Springer Nature remains neutral with regard to jurisdictional claims in published maps and institutional affiliations. 